\title{
Correspondence
}

To the Editors

\section{Post COVID-19 vaccination, increased blood viscosity and impact on laboratory investigation results}

Sri Lanka Journal of Child Health, 2021: 50(4): 747

DOI: http://doi.org/10.4038/sljch.v50i4.9908

(Key words: Post Covid-19 vaccination, Increased blood viscosity, Laboratory investigation results)

Dear Editors,

COVID-19 vaccine is a new vaccine for controlling the pandemic. The vaccine is already recommended for teenage children. After vaccination, the human body will create protective SARS-CoV-2 antibodies and result in active protective immunity. After a COVID vaccination, there will be increased blood viscosity due to increased immunoglobulin level ${ }^{1}$. An interesting concern is on the impact of vaccination on the diagnostic laboratory.

There is no doubt that the vaccine can change the way for using a SARS-CoV-2 serological test result interpretation. Moreover, it might also result in an unusual aberration of clinical chemistry laboratory results. For example, thyroid function test which is a common test for diagnosis of thyroid disorders in paediatric endocrinology might be changed after COVID-19 vaccination. This is explainable by the effect of blood viscosity change after vaccination. The high viscosity can result in false high blood thyroid hormone result ${ }^{2}$. Some recent reports on post vaccination Graves' disease appearance ${ }^{3}$ might be explained by the false positivity in laboratory investigation. This is an important consideration in interpretation of laboratory results in the period that paediatric COVID-19 vaccination is widely used. It is necessary to have a re-check for a possible false positive result before making management decisions.

\section{References}

1. Joob B, Wiwanitkit V. Expected viscosity after COVID-19 vaccination, hyper- viscosity and previous COVID-19. Clinical and Applied Thrombosis/ Hemostasis 2021; 27:10760296211020833. https://doi.org/10.1177/107602962110208 33

PMid: 34142570 PMCid: PMC8216419

2. Tamagna E, Hershman J, Premachandra BN. Circulating thyroid hormones in a patient with hyper-viscosity syndrome. Clinica Chimica Acta 1979; 93(2): 263-8. https://doi.org/10.1016/00098981(79)9009 8-6

3. Vera-Lastra O, Ordinola Navarro A, Cruz Domiguez MP, Medina G, Sánchez Valadez TI, Jara LJ. Two cases of Graves' disease following SARS-CoV-2 vaccination: An autoimmune/ inflammatory syndrome induced by adjuvants. Thyroid 2021 May 3. Online ahead of print https://doi.org/10.1089/thy.2021.0142 PMid: 33858208

Khon Khon ${ }^{1}$, *Rujitika Mungmungpuntipantip ${ }^{1}$, Viroj Wiwanitkit ${ }^{2}$

${ }^{1}$ Private Academic Consultant

${ }^{2}$ Honorary Professor, Dr. DY Patil University, Pune, India

*Correspondence: rujittika@gmail.com

iD https://orcid.org/ 0000-0003-0078-7897

The author declares that there are no conflicts of interest.

Open Access Article published under the Creative Commons Attribution CC-BY (C) (i) License 